\title{
O BRINCAR E O DESENVOLVIMENTO HUMANO
}

\section{The child playing and the human development}

Cloves Amorim ${ }^{1}$

Léo Peruzzo Júnior ${ }^{2}$

Moyles, J. R. et. Col. (2006). A excelência do brincar. Porto Alegre: Artmed.

É impossível pensar em infância sem se remeter ao brincar. Há mais de uma década, no Curso de Psicologia da PUCPR, temos pesquisado e estudado o brincar Amorim (1994); Amorim, Bach \& Tawamoto (1995), Amorim, Oliveira \& Mariotto (1997), Amorim, Carli, Moser \& Santos (2003), Amorim \& Presa (2004), Amorim, Todeschi \& Pedroso (2006). Ao longo deste tempo, temos acompanhado a produção brasileira, desde os trabalhos pioneiros da Dra. Eda Bomtempo, na USP, passando pelas valiosas contribuições de Friedman (1992), Santos (1997, 1999, 2000 e 2001), Lopes (2000), Macedo ( 2005) para citar apenas alguns autores.

Entre as traduções, destacamos a obra de Moyles (Só brincar: o papel do brincar na educação infantil, 2002), que marcou um significativo impacto na área. Agora temos a honra e o prazer de apresentarmos outra obra desta autora e seus colaboradores: "A ex celência do brincar".

Janet R. Moyles é professora titular de educação na Universidade de Leicester, onde é responsável pela educação inicial e pela formação de professores de educação infantil. É a organizadora da presente obra. Este livro está dividido em quatro partes ao longo de 15 capítulos. Encontramos, ainda, introdução e posfácio, elaborados pela própria organizadora.

Na introdução (p. 11 a 21), a autora informa que o livro tem como principal objetivo gerar e estimular novos pensamentos e animar o debate sobre questões relativas à aprendizagem e ao brincar, ao currículo nacional e à relação com o brincar na educação infantil. Ainda na introdução, destaca que o livro se destina a profissionais que trabalham com crianças de 03 a 08 anos de idade. Também destaca uma taxionomia do brincar infantil.

A parte I apresenta quatro capítulos e se intitula: A cultura do brincar e a infância. O capítulo 1 - O brincar e os usos do brincar, de autoria de Peter K. Smith, destaca a concepção de Zona de Desenvolvimento Proximal e argumenta que o adulto desempenha um papel chave como auxiliar da

1 Doutorando em Psicologia na Universidade Complutense de Madrid, Especialista em Didática e em Bioética, docente da PUCPR.

Endereço: Av. São José, no 700, ap. 5- A. Bairro Cristo Rei - CEP 80050-350, Curitiba - PR

E-mail: clovesamorim@hotmail.com

2 Acadêmico do Curso de Filosofia $4 \stackrel{0}{0}$ período.

Psicol. Argum., Curitiba, v. 24, n. 46 p. 91-94, jul./set. 2006. 
aprendizagem infantil. Afirma que "As idéias de Vygotsky \& Bruner são valiosas para o educador que trabalha com educação infantil, ao indicar como os adultos podem, de modo muito efetivo, intensificar e apoiar o brincar e o desenvolvimento da criança", (p. 38). No capítulo 2 - O brincar em diferentes culturas e em diferentes infâncias, Audrey Curtis enfatiza que são muitas e variadas as concepções do brincar, mas a maioria inclui a idéia do brincar como experiência prazerosa, que não tem um produto final e é intrinsecamente motivada. Conclui que, apesar do brincar como atividade na infância ser aceito em todas as sociedades, sua importância não é reconhecida na mesma extensão no mundo todo.

Gênero é a temática do capítulo 3, Jane Hislam apresenta "Experiências do brincar diferenciadas pelo sexo e pelas escolhas das crianças". Aponta a necessidade dos educadores refletirem sobre: envolver a criança na escolha, na discussão e no planejamento do brincar; compreender que nem sempre a brincadeira acontece no canto destinado ao faz de conta; aceitar que os adultos precisam reconhecer e participar do brincar infantil; ouvir e observar cuidadosamente. David Brown é o autor do capítulo 4 - "O brincar, o pátio de recreio e a cultura da infância". Ele examina detalhadamente as maneiras como os espaços para brincar nas escolas são utilizados pelas crianças para criar um tipo muito diferente do mundo de brincar "para além da porta da sala de aula". Conclui que o pátio de recreio oferece um ambiente para um fórum cultural dentro do qual as crianças podem criar e recriar significado a partir da soma de suas experiências.

A parte II, do capítulo 05 ao 08, tem como temática o brincar, a escolarização e as responsabilidades. Ângela Anning, autora do capítulo 5 - ("O brincar e o currículo oficial". De volta ao básico: uma visão alternativa). Neste capítulo, a autora enfatiza que as crianças estão no âmago do currículo e que oportunidades holísticas baseadas no brincar devem ser centrais na aprendizagem e no ensino da primeira infância. Conclui a autora, "Seria uma grande realização educar crianças pequenas para que se tornassem adultos com esse senso de curiosidade e divertimento." (p. 93).

A experiência de sala de aula não precisa ser aversiva, monótona ou chata. No capítulo 06, Lesley Abbott nos brinda com "Brincar é bom!". Desenvolvendo o brincar em escolas e salas de aula. Afirma Abbott, "o brincar é a maneira de a criança aprender e que negligenciar ou ignorar 0 papel do brincar como meio educacional é negar a resposta natural da criança ao ambiente e, na verdade, à própria vida! (p. 94). Prossegue a autora, "O papel do brincar no currículo do ensino fundamental não deve ser do interesse dos educadores individualmente: é essencial que ele seja discutido entre os profissionais em um contexto compartilhado, para que se desenvolvam crenças compartilhadas, entendimento mútuo, coerência e consistência de abordagem". Gentilmente Abbott lista cinco objetivos do capítulo, que são plenamente atendidos: 1) definição do brincar; 2) o valor da pesquisa para informar e enriquecer a prática; 3) observação, avaliação e registro de experiências lúdicas; 4) o papel do brincar no currículo; 5) o papel dos adultos na provisão do brincar.

No capítulo 7 - Neil Kitson aborda 0 brincar de faz de conta, com o curioso título: "Por favor, Srta. Alexander: você pode ser o ladrão? O brincar imaginativo: um caso para a intervenção adulta.". Inicialmente lista os elementos necessários para o brincar imaginativo: 1) Desempenho de papel imitativo; 2) Faz-de-conta com relação a brinquedos; 3) Faz-de-conta verbal; 4) Persistência no desenvolvimento do papel; 5 5) Interação e 6) Comunicação verbal. Na página 119 , conclui 0 autor: "O brincar imaginativo é importante para 0 desenvolvimento cognitivo, social e emocional da criança. Ele progride do brincar objetal para o brincar simbólico e, finalmente, para o brincar sociodramático. E o brincar sociodramático oferece um grande potencial de aprendizagem para aqueles que trabalham com crianças pequenas". O capítulo 8 encerra a segunda parte. Peter Heaslip se ocupa do brincar em sala de aula. Afirma o autor, "a escola tem uma responsabilidade cada vez maior de garantir que as crianças não sejam privadas das oportunidades de descobrir a respeito de si mesmas e de seu mundo e que tenham o direito de aprender de uma maneira que seja apropriada para elas - por meio do seu brincar" (p. 131).

Já na introdução, ao comentar a obra, Moyles informa que na terceira parte "O brincar e o currículo dos primeiros anos" quatro autores examinam a prescrição de um currículo para 0 brincar. No capítulo 9, Nigel Hall fala sobre o potencial extraordinariamente rico do brincar, em relação ao processo de letramento na criança e utiliza a dramatização em vários ambientes esti- 
muladores como a base para explorar e ampliar a qualidade das experiências infantis de leitura e escrita.

No capítulo 10, "Aprendizagem experiencial no brincar e na arte" da autoria de Roy Prentice, se inicia com os dois objetivos do capítulo: a) Considerar a natureza e a qualidade da relação entre os processos e procedimentos da arte e certos aspectos do brincar; b) Ajudar os professores a criar as condições pelas quais a criança pequena pode ser iniciada na arte como uma maneira de conhecimento, por meio de uma abordagem estruturada do brincar. Na página 151, o autor faz um alerta "O brincar é, potencialmente, uma das melhores formas de aprendizagem, mas ele pode facilmente ser amorfo e deixar a desejar em termos de desenvolvimento, satisfação e desafio pessoal, passando a ser apenas uma vaga terapia ou algo para encher o tempo". O 11‥ Capítulo, de dupla autoria, Jeni Riley \& Jane Savage, aborda o brincar, a aprendizagem e a ciência. As autoras são enfáticas: "Nós acreditamos realmente que atividades lúdicas cuidadosamente planejadas e desafiadoras podem proporcionar essa experiência de aprendizagem científica convincente e apropriada, não apenas nas salas de aula de educação infantil, mas em todo ensino fundamental".

O último capítulo da terceira parte, capítulo 12 - "A matemática e o brincar" traz as contribuições de Rose Griffiths. O foco é aprender bem matemática por meio do brincar. Para a autora, se quisermos que as crianças se tornem bons matemáticos, precisamos demonstrar para elas que a matemática é divertida e útil e que pode ser uma atividade sociável e cooperativa, assim como uma atividade tranqüila e individual.

A quarta parte do livro, Examinando e avaliando o brincar, tem três capítulos. No capítulo 13, Christine Pascal e Tony Bertran enfatizam a necessidade de qualidade na oferta do brincar, mas afirmam veementemente que o conceito de qualidade só pode ser definido pelas reflexões e conclusões compartilhadas por profissionais experientes. Eles sugerem uma estrutura criteriosa, com bases teóricas, para o profissional identificar, avaliar e monitorar a qualidade do brincar que está proporcionando às crianças.

Capítulo 14 - Observando o brincar na primeira infância, de autoria de Victoria Hurst, docente da Universidade de Londres, inicia com a afirmativa "a observação é essencial aos proces- sos educacionais da primeira infância. Ela nos dá as informações factuais das quais dependem os outros processos, incluindo o monitoramento e a avaliação do progresso de cada criança". Informa que neste capítulo examina três aspectos principais do brincar: 1) A observação, em ambientes educacionais, do momento presente, da cena que está acontecendo; 2) Como a observação é - e pode ser - usada como um instrumento de ensino-aprendizagem e 3) $\mathrm{O}$ registro das evidências da observação. Conclui a autora "Os educadores dos primeiros anos são as pessoas que ajudam as crianças a construírem as pontes de entendimento entre suas experiências individuais e os conhecimentos mais formais sobre 0 mundo, dos quais depende a educação posterior.

Tina Bruce é a autora do 15ํ․ Capítulo: "O brincar, o universo e tudo!". A autora defende o direito de brincar, afirma que por meio do nosso brincar durante a infância nós nos tornamos parceiros do nosso futuro. Destaca que estamos vendo uma erosão da valorização do brincar de fluxo livre, as crianças freqüentam a escola formal por longas horas, começando em idades cada vez mais precoce e isso está diminuindo a possibilidade do brincar de fluxo livre. Não se opõe a freqüência da educação infantil, mas uma educação de boa qualidade não pode negligenciar 0 brincar.

O livro ainda oferece uma vasta e atualizada bibliografia com mais de 240 referências. Indicamos a leitura da obra, com especial recomendação para aqueles que se ocupam profissionalmente da infância. Educadores e profissionais da Educação infantil seguramente ampliarão o repertório de competência e ternura no trato com crianças. Boa leitura.

\section{Referências}

Amorim, C. Brinquedoteca: um mergulho no brincar. Revista Práxis, Curitiba, 2, 10-11. 1994.

Amorim, C., Bach, J. G., \& Tawamoto, J. M. A (1995, nov.). Utilização e principais concepções do brinquedo em instituições da cidade de $\mathrm{Cu}$ ritiba. Revista Psicologia Argumento. Curitiba, 13(17), p. 61-71 
Amorim, C., Oliveira, M. A. C., \& Marioto, R. M. M. (1997, nov.). A Psicologia do brinquedo. Revista Psicologia Argumento. Curitiba, 15(21), p.9-30.

Amorim, C., Carli, R. M. N., Moser, M. D. L. \& Santos, G. (2003). O brincar de meninos e meninas da quarta série do ensino fundamental. Paper apresentado na Reunião anual da ABPMC. Campinas.

Amorim, C., \& Presa, E. P. (2004). A brincadeira como forma terapêutica. In: Voz do Paraná. Curitiba, 48(1970), p. 06-07.

Amorim, C., Todeschi, M. S., \& Pedroso, P. C. brincar como recurso de inclusão, In Parolin, I. ( org.). (2006). Aprendendo a Incluir e Incluindo para aprender. São José dos Campos: Pulso Editorial.
Friedman, A. (org.). (1992). 0 direito de brincar: a brinquedoteca. São Paulo: Escrita: ABRINQ .

Lopes, M.G. (2000). Jogos na educação: criar, fazer e jogar. São Paulo: Cortez.

Macedo, L, Petty, A. L. S., \& Passos, N. C. (2005). Os jogos e o lúdico na aprendizagem escolar. Porto Alegre: Artmed.

Moyles, J. R. (2002). Só brincar? O papel do brincar na educação infantil. Porto Alegre: Artmed.

Santos, S. M. P (org.). (2000). Brinquedoteca: a criança, o adulto e o lúdico. Petrópolis: Vozes.

Santos, S. M. P. (1997). O Lúdico na formação do educador 